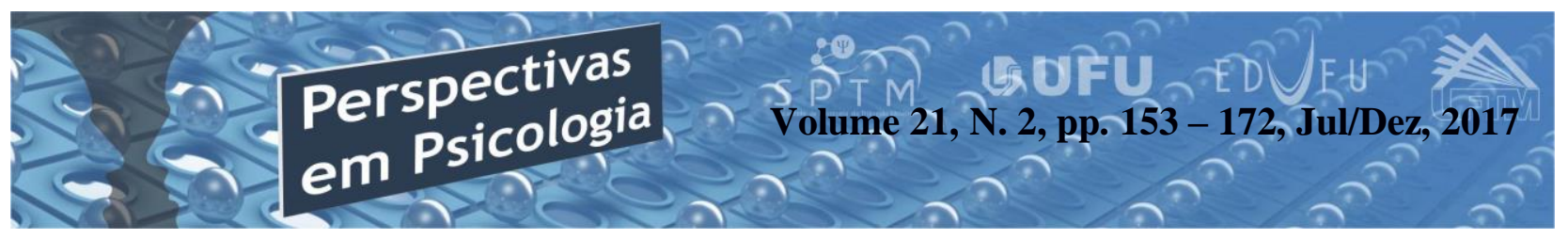

\title{
ESQUEMAS INICIAIS DESADAPTATIVOS E PRÁTICAS PARENTAIS: ESTUDO COMPARATIVO ENTRE PRESOS POR ROUBO E TRÁFICO
}

\author{
Ana Paula Costa de Cristo \\ Dayane Denck Froeder \\ Adriana Aparecida Garbin \\ (Centro Universitário Fundação Assis Gurgacz, Cascavel-PR)
}

\begin{abstract}
Resumo
O contexto atual da sociedade esboça um crescente índice de criminalidade, que tem despertado interesse de estudiosos para o desenvolvimento de pesquisas com a população prisional. $\mathrm{O}$ presente estudo foi realizado em uma penitenciária de Cascavel/PR e teve como objetivo levantar características gerais da amostra, que foram 22 detentos do sexo masculino condenados por roubo e tráfico. Foram utilizados alguns instrumentos, como: questionário sociodemográfico, inventário de estilos parentais e questionário de esquemas de Young. Através das análises pode ser evidenciado que nenhuma variável avaliada apresentou diferença significativa entre os grupos estudados. Logo, a correlação de Pearson identificou uma correlação positiva entre algumas práticas parentais (monitoria positiva, negligência, abuso físico, disciplina relaxada e monitoria negativa) e alguns esquemas iniciais desadaptativos (autossacrifício, padrões inflexíveis, busca por aprovação, negativismo e postura punitiva). Os resultados contribuíram para a percepção quanto às práticas parentais e os esquemas iniciais desadaptativos entre os detentos pesquisados.
\end{abstract}

Palavras-chave: esquemas; desadaptativos. população prisional; estilos parentais.

\section{Abstract \\ Initial Disadaptative Schemes and Parental Practices: Comparative Study Between Prisoners for Theft and Traffic}

The current context of society outlines an increasing crime rate which has attracted interest from scholars for the development of research with the prison population. and aimed to search general characteristics of 22 male inmates convicted of robbery and trafficking. Some instruments were used, such as: a sociodemographic questionnaire, an inventory of parental styles and a questionnaire on Young's schemes. Through the analyzes it can be evidenced that no evaluated variable presented significant difference between the studied groups. Therefore, Pearson's correlation identified a positive correlation between some parenting practices (positive monitoring, neglect, physical abuse, relaxed discipline and negative monitoring) and some initial maladaptive schemes (self-sacrifice, inflexible standards, seeking for approval, negativism, and punitive posture). The results contributed to the perception of parental practices and the initial maladaptive schemes among the inmates surveyed.

Keywords: schemes; disadaptive; prisoners; parental practices. 


\section{1 - Introdução}

O presente estudo investigou relações entre os Esquemas Iniciais Desadaptativos e Práticas Parentais que mais prevaleceram entre os detentos condenados por roubo e tráfico, para isso, embasou-se nas perspectivas da Teoria dos Esquemas de Young.

Por meio deste estudo apresentamos os principais dados referentes às características sociodemográficas e relativas à prática criminal, como, por exemplo, o histórico criminal, a escolaridade, o estado civil e a avaliação dos esquemas iniciais desadaptativos e das práticas parentais que mais prevaleceram na amostra. Além do subsídio científico, esta pesquisa visa contribuir para a construção do conhecimento acerca dessa população, auxiliando para que futuras pesquisas sejam realizadas.

Conforme mencionado por Wainer e Rijo (2016), a Terapia de Esquemas representa um avanço no tratamento de indivíduos que apresentam um quadro complexo, e tem concedido aos estudiosos uma base valiosa acerca das necessidades psíquicas consideradas fundamentais para o desenvolvimento humano. Quando mencionamos o desenvolvimento humano, não podemos deixar de lado a tarefa atribuída aos pais de "criar filhos saudáveis", que Gomide (2006) compreende como modelos de estilos parentais, os quais são reflexos das medidas adotadas pelos pais na educação dos filhos. Portanto, a partir desse olhar, buscou-se, com a aplicação um questionário sociodemográfico e da aplicação do Inventário de Estilos Parentais e Questionário de
Esquemas Iniciais Desadaptativos (YSQ-S3) analisar se existem correlações entre as práticas parentais e esquemas iniciais desadaptativos entre presos por crime de roubo e crime de tráfico.

\section{2 - Terapia dos Esquemas}

Conforme Fioravante e Castañon (2014), por meio do desenvolvimento da terapia cognitiva, em meados da década de 1960, propõe-se uma psicoterapia na qual o ser humano se apresenta ativo ao fazer escolhas no contexto em que está envolvido. Nesse sentido, o indivíduo pode apresentar mudanças em comportamentos indesejáveis por intermédio de transformações em sua mente, vindo a apresentar novas cognições, as quais afetam tanto as emoções quanto o comportamento humano e podem ser monitoradas e alteradas.

Ao propor a terapia do esquema Jeffrey E. Young e colaboradores ampliam os conceitos da terapia cognitivo-comportamental de Aaron Beck, que sofreu influências de várias teorias, dentre elas a terapia Cognitiva Comportamental e a Gestalt (Young, Kloslko \& Weishaar, 2008).

Sendo assim, a terapia do esquema surge da necessidade de se trabalhar com pacientes com transtornos mais severos, pois esses não possuíam a capacidade de responder a algumas intervenções propostas pela terapia cognitiva-comportamental. Algumas das suas limitações estariam ligadas à capacidade de identificação de problemas, à motivação para a realização de tarefas de casa, ao autocontrole e a engajar-se em um relacionamento 
colaborativo com o terapeuta (Cazassa \& Oliveira, 2008).

Young e seus colaboradores criaram, nessa perspectiva, uma nova proposta que proporciona um novo sistema psicoterápico, principalmente nos pacientes com transtornos psicológicos crônicos (Young, Kloslko \& Weishaar, 2008).

Como descrito por Rijo (2009), os esquemas ou estruturas cognitivas são conceituados com nomenclaturas diferentes por diversos autores, no entanto, independente da definição, estes correspondem às estruturas em que as informações estão internamente dispostas e ao modo como se representam. Segundo o autor, é por meio dos esquemas que os indivíduos atribuem significado às informações.

Todavia, no modelo de terapia dos esquemas desenvolvido por Young, enfatiza-se a investigação das experiências iniciais da vida do paciente, buscando as origens dos distúrbios psicológicos durante períodos precoces do seu desenvolvimento, como a infância e a adolescência (Young, Kloslko \& Weishaar, 2008).

Conforme Young (2003), os Esquemas Iniciais Desadaptativos (EIDs, de ora em diante) podem ser considerados como os níveis mais profundos da cognição dos indivíduos e definidos como as crenças, os afetos, os registros da memória que as pessoas possuem como verdades sobre si e acerca do meio. Ressalta-se que é na fase da infância que essas crenças irão se desenvolver e poderão interferir nas vivências deste indivíduo como um todo (Young, Kloslko \& Weishaar, 2008).
Segundo Isoppo (2012), o esquema funciona como um filtro, assimilando informações selecionadas e organizando estímulos consistentes. Por meio dessa estruturação, o indivíduo consegue se orientar com relação ao tempo e ao espaço, em relação aos seus esquemas e, ainda, categorizar e interpretar experiências significativas (Rocha, Formiga \& Lopes, 2014).

\subsection{Esquemas Iniciais Desadaptativos}

Segundo Young (2003), os EIDs são considerados como partes significativas da cognição, em que as estruturas se desenvolvem a partir de crenças, afetos e memórias que podem ser tomadas como verdadeiras ou não, de forma idiossincrática; neste caso, os sentimentos formados durante a infância e a adolescência podem influenciar no processamento das experiências futuras (Rocha, Formiga \& Lopes, 2014).

De acordo com Isoppo (2012), a teoria de esquema proposta por Young é uma evolução do modelo cognitivo de Aaron Beck para o tratamento de transtornos de personalidade, porém, enfatizando em uma cognição mais profunda como os EIDs (Cazassa \& Oliveira, 2008).

Os EIDs exerceriam a capacidade de modificar as interpretações que o indivíduo tem sobre os acontecimentos, podendo, assim, distorcer a realidade, e, conforme Isoppo (2012), ativar as crenças do indivíduo, envolvendo tanto sensações emocionais e corporais, como elementos biológicos (Rocha, Formiga \& Lopes, 2014). 
Young, Kloslko e Weishaar (2008) propuseram um modelo com 18 EIDs, que estão agrupados em cinco categorias chamadas de domínios de esquemas, a saber: domínio I: Desconexão e Rejeição; domínio II: Autonomia e Desempenho Prejudicados; domínio III: Limites Prejudicados; domínio IV: Direcionamento para o outro; domínio V: Supervigilância e Inibição.

\subsection{Práticas Parentais}

Segundo Mondin (2008), várias pesquisas estão sendo conduzidas em nossa sociedade com o intuito de investigar e de analisar o papel das práticas parentais e seu impacto sobre o desenvolvimento das crianças. Ao pesquisar sobre práticas parentais, podemos evidenciar que, além deste termo, outros conceitos como estilos parentais, ou cuidados parentais, são usados para caracterizar a forma de relacionamento entre pais e mães com seus filhos por meio de seus comportamentos (Macarini et al., 2010).

De acordo com Lubi (2003), as famílias, por serem formadoras do núcleo familiar e o primeiro contexto de socialização, influenciam intensivamente no comportamento e no desenvolvimento das crianças. Por conseguinte, os estilos parentais passam a ter valor significativo para o indivíduo, sendo os pais reforçadores, fontes de afeto e também modelos de aprendizagem para as crianças.

Pioneira nos estudos sobre estilos parentais, a autora Baumrind (1966) afirma que as primeiras relações entre os pais e filhos são fundamentais para o desenvolvimento da criança, e, por meio dessa investigação, a autora identificou três modelos de estilos parentais: o autoritário, o permissivo e o autoritativo. A autora descreve, inclusive, o modelo não envolvido, o qual mostra indiferença ou negligência para com o filho.

Para Boeckel e Sarriera (2006), pais autoritários prezam pela obediência, são punitivos, por vezes utilizam da medida de força para se manifestarem e se imporem, são extremamente controladores, prejudicando o desenvolvimento e a autonomia da criança, como consequência, isso facilita os comportamentos de submissão, de rejeição, de insatisfações e de dependência.

Os pais com o estilo parental autoritativo estabelecem regras para o comportamento dos seus filhos que são eficientes e eficazes, observam sua conduta, apoiando e gratificando atitudes positivas e corrigindo as negativas, pode-se considerar pais com o estilo autoritativo aqueles que combinam as dimensões de responsividade e exigência de forma equilibrada (Lila, 2009).

De acordo com Cardoso e Veríssimo (2013), o último estilo de pais, que são os permissivos, possuem atitudes condescendentes e tolerantes diante dos comportamentos e desejos da criança, geralmente são pais menos punitivos e pouco exigentes de regras e rotinas, mas que, por vezes, ficam descontentes por não terem o controle da criança.

Sampaio (2007) afirma que muitos pesquisadores criaram modelos teóricos que visam avaliar as práticas educativas parentais e como elas podem afetar o desenvolvimento dos filhos, sendo que muitos desses modelos 
favorecem o desenvolvimento de trabalhos preventivos, de avaliação, de orientação e de intervenção. Dessa forma, o Inventário de Estilos Parentais (IEP) é um modelo teórico composto pelo conjunto de sete práticas educativas que avaliam os estilos parentais, cinco delas estão relacionadas ao desenvolvimento de comportamentos antissociais como abuso físico, punição inconsistente, disciplina relaxada, monitoria negativa e negligência, já em relação ao desenvolvimento de comportamentos prósociais são a monitoria positiva e o comportamento moral (Gomide, 2006).

Vários estudos envolvendo a aplicação do Inventário de Estilos Parentais tem sido desenvolvido, sendo que um dos recentes é conduzido por Rocha e Carvalho (2012), no qual as autoras avaliaram se existia diferença nas práticas parentais entre um grupo de homicidas reais e homicidas virtuais, em que constataram que, no grupo de homicidas reais, a prática negativa de abuso físico era mais frequente e intensa, o que fomenta a importância de estudar de forma mais aprofundada a população forense.

Gomide (2006) propõe um modelo teórico que possibilita avaliar práticas educativas que compõem os estilos parentais, para avaliação conta-se com o Inventário de Estilos Parentais (Gomide, 2006), o qual possui avaliação favorável pelo Conselho Federal de Psicologia como teste psicológico.

\subsection{Condutas Desviantes em Crimes}

Para Silveiras e Gouvêa (2012), os indivíduos tendem a aceitar como verdadeira a ideia de que o social possui uma normatividade, algo que deve ser seguido por indivíduos; além disso, acreditam que aqueles que não as seguem devem ser punidos com o intuito de reestabelecer a normalidade da estrutura social.

Segundo Rocha, Formiga e Lopes (2014), vários estudiosos têm buscado compreender fatores que influenciam na realização de atividades delitivas e na execução de comportamentos desviantes. De acordo com os autores, por muito tempo os fatores individuais eram de pouca ou nenhuma relevância; destacavam-se apenas os crimes em si. No entanto, com o desenvolvimento da sociedade e a partir de seus constructos, os aspectos biológicos passaram a integrar os estudos dessas populações. Essas pesquisas, porém, referem-se a um fenômeno complexo, que estimula a necessidade de explorar esse campo em busca de resultados sobre o tema.

De acordo com Velho (2003), o indivíduo com comportamento desviante por muito tempo foi encarado a partir de um olhar médico, no qual buscava-se distinguir o "são" do "não são"; e até mesmo do insano. Como consequência desse modelo cultural, evidenciou-se um contexto em que os indivíduos pudessem ser rotulados como "normais e anormais" e, desse modo, fossem categorizados, tornando perceptível a existência de comportamentos mais controláveis do que outros.

$$
\text { Rijo, Brazão e Capinha }
$$
mencionam que, em regra, o comportamento antissocial no meio social é concebido como um 
padrão que viola os direitos dos outros, por infligir normas e leis. De acordo com os autores, estes comportamentos antissociais podem ser tanto "de oposição ligeira até aqueles qualificados como crime", são considerados como aversivos principalmente por aqueles que foram vítimas ou para aqueles que convivem com estes.

Vários aspectos são relevantes para a exibição de comportamentos considerados como inadequados ou incorretos perante a sociedade, em um estudo conduzido por Rocha, Formiga e Lopes (2014), constatou-se que a personalidade é um dos fatores que influencia em como esses indivíduos irão interagir com o meio. Por outro lado, Velho (2003) menciona que é preciso analisar como a vida sociocultural desse indivíduo é representada e percebida, bem como as pressões favoráveis ao comportamento socialmente desviado, embora sustente que se compreenda que, não necessariamente, os comportamentos desviantes são comportamentos delitivos.

Mendes e Vieira (2012), em pesquisa sobre os comportamentos desviantes, evidenciaram que os estudos sociais sobre esses comportamentos buscam compreender o motivo pelo qual são considerados como desviantes e o modo como estes comportamentos se manifestam no contexto social.

Algumas transgressões resultam em penalidades para os indivíduos, isso porque infringem as leis, conforme mencionado por Mafra (2012). A Constituição Federal é a lei máxima que rege, estabelece e organiza uma sociedade. Nesse sentido, o Art $5^{\circ}$, da
Constituição da República Federativa do Brasil, diz respeito aos direitos e aos deveres individuais e coletivos e estabelece que: "ninguém pode ser obrigado a fazer ou deixar de fazer alguma coisa senão em virtude da lei”. No contexto da atual pesquisa, o comportamento desviante, e neste caso delituoso, já que infringiu as leis vigentes, foram os crimes de roubo e de tráfico, enquadrados no Art. $^{\circ} 33$, caput, da Lei $\mathrm{n}^{\circ}$ 11.343/06, no $\mathrm{Art}^{\circ} 157$, do Código Penal decreto e na Lei $\mathrm{n}^{\circ}$ 2.848/40.

De acordo com Silva (2013), existem vários tipos de comportamentos desviantes, e, ao discursar sobre esses, pode-se falar sobre ações que violentam a qualidade de vida dos indivíduos. Portanto, considerando que é de grande relevância estudar as emoções, as sensações corporais e as cognições dos indivíduos e, ainda, que poucos estudos com a população prisional têm sido realizados, pretendeu-se com esta pesquisa buscar compreender a percepção de indivíduos condenados por crime de roubo e indivíduos condenados por crime de tráfico.

De fato, os indivíduos desta pesquisa praticaram comportamentos desviantes e, no caso, também delitivos. O profissional de psicologia, nesse contexto, deve atentar-se com relação a sua postura, pois, segundo Andriola (2016), a terapia de esquemas pode ser considerada como uma abordagem que desperta a necessidade do profissional de psicologia se dispor emocionalmente ao paciente que está em processo terapêutico, isto não somente porque na ocasião o paciente expõe suas fragilidades mais íntimas, mas, porque, nesta relação, o 
terapeuta torna-se agente de mudança. Afinal, um dos objetivos de manter uma pessoa em cárcere é a sua ressocialização, a terapia de esquemas foi desenvolvida para promover intervenções em pacientes "difíceis e resistentes".

Por fim, considerando que a Terapia de Esquema busca avaliar os esquemas iniciais desadaptativos e, ainda, que os estudos sobre os estilos parentais auxiliam no entendimento quanto às práticas parentais adotadas pelos genitores na educação de seus filhos, buscou-se atrelar estas duas temáticas no estudo com presos por crime de tráfico e presos por crime de roubo, buscando conhecer melhor essa população e acreditando que, ao conhecê-la, propostas de intervenções poderão ser sugeridas, já que na proposta de vários autores é necessário conhecer e, a partir disso, tentar modificar o esquema a fim de conseguir novos estilos de enfrentamento diante das demandas do contexto social, fazendo com que os indivíduos deixem de responder ao meio de forma desadaptativa (Young, Kloslko \& Weishaar, 2008).

\section{3 - Métodos}

A pesquisa foi desenvolvida em uma Penitenciária do Estado do Paraná, refere-se a um estudo transversal de caráter descritivo, e de acordo com os procedimentos técnicos pode ser delineada como de levantamento, para a análise dos dados, a referida problemática foi abordada de forma quantitativa. Primeiramente, o projeto de pesquisa foi submetido ao comitê de ética em pesquisa com seres humanos, foi analisado e aprovado, após a aprovação, foi estabelecido o contato com o diretor da unidade prisional, explicado objetivo do estudo e solicitada a permissão para a realização da pesquisa.

A amostra da pesquisa contou com a participação de 22 indivíduos, sendo 11 (onze) condenados por crime de tráfico e 11 (onze) condenados por crime de roubo. A seleção desses indivíduos ocorreu mediante um sorteio dentre os detentos de cada uma das populações. A referida pesquisa contou com os seguintes critérios de inclusão: ser indivíduo do sexo masculino, estar condenado e cumprindo pena na unidade prisional em que se realizou a pesquisa, ter cometido crime de tráfico ou crime de roubo, os detentos devem ter convivido durante a infância com o pai e a mãe e concordar em participar da pesquisa assinando o termo de consentimento livre e esclarecido (TCLE). Quanto aos critérios de exclusão foram: estar detido e no entanto não estar cumprindo pena por tráfico ou roubo; não estar cumprindo pena na penitenciária em que foi realizada a pesquisa e não concordar em participar da mesma.

Os procedimentos éticos envolvidos nesta pesquisa estão em conformidade com a Resolução 466, do CNS, de 12 de dezembro de 2013. Embora toda pesquisa possa apresentar riscos, sejam físicos, psíquicos, morais, intelectuais, culturais ou espirituais aos indivíduos participantes, durante a coleta dos dados, não houve a necessidade de realizar nenhum encaminhamento.

Logo, a pesquisa mostrou muitos benefícios, contribuiu para que a comunidade científica obtivesse um estudo sobre os esquemas iniciais desadaptativos e estilos 
parentais que mais prevalecem entre detentos por roubo e por tráfico. Para os apenados, o benefício foi de se pensar em formatações de futuras propostas de intervenções; já para a comunidade geral, foi a possibilidade de, a partir dos dados coletados e resultados apresentados, reconhecer principais EIDs e estilos parentais dos presos, peculiaridades acerca da personalidade destes detentos e fenômenos por trás destes.

Foi aplicado o questionário sociodemográfico com o objetivo de mapear características como: idade, sexo, estado civil, escolaridade, dentre outras. Também foi utilizado o Inventário de Estilos Parentais (IEP), de Gomide (2006), a aplicação desse instrumento teve como objetivo verificar as diferentes maneiras adotadas pelos pais na educação de seus filhos. O inventário é composto por 42 perguntas, sendo necessário que as questões fossem respondidas com veracidade e tranquilidade, levando em consideração o contexto familiar em que estava inserido na infância e adolescência. O inventário é composto por sete práticas educativas, onde duas são consideradas práticas positivas - monitoria positiva e comportamento moral - e cinco práticas negativas - abuso físico, disciplina relaxada, monitoria negativa, negligência e punição inconsistente. As respostas são distribuídas em uma escala likert, em que as opções são nunca, às vezes e sempre.

Para a análise dos EIDs o instrumento utilizado foi o Questionário de Esquemas Iniciais Desadaptativos de Young (Young Schema Questionnaire YSQ-S3 de Jeffrey Young), traduzido e adaptado por J. Pinto
Gouveia; D. Rijo e M. C. Salvador (2005 como citado em WAINER et al., 2016). Esse instrumento avalia os dezoito esquemas iniciais desadaptativos que se encontra inseridos em cinco domínios que são: Desconexão e Rejeição, Autonomia e Desempenho Prejudicados, Limites Prejudicados, Direcionamento para o Outro, Supervigilância e Inibição.

De acordo com a alínea do art. $2^{\circ}$, do Código de Ética Profissional do Psicólogo, "ao psicólogo é vedado: realizar diagnósticos, divulgar procedimentos ou apresentar resultados de serviços psicológicos em meios de comunicação, de forma a expor pessoas, grupos ou organizações" (CFP, 2014, p. 11); devido a isso, o inventário não constará em anexo e a orientadora se responsabilizará em guardar os resultados da aplicação do Inventário de Estilos Parentais e do Questionário de Esquemas Iniciais Desadaptativos. Isso ficou explícito conforme carta encaminhada ao Comitê de Ética de Pesquisa com Seres Humanos da faculdade.

\section{4 - Resultados}

Apresentamos abaixo os dados oriundos desta pesquisa, estes compilam os resultados referentes à aplicação dos instrumentos: Questionário Sociodemográfico, Inventário de estilos parentais e YSQS3. A amostra total é composta por 22 indivíduos, sendo que, dentre estes, 11 foram detidos por crime de tráfico e 11 por crime de roubo, todos os participantes são do sexo masculino. 
Em um primeiro momento, apresentamos informações obtidas por meio de questionário sociodemográfico, posteriormente os esquemas iniciais desadaptativos e os estilos parentais que mais prevaleceram entre as populações e, por último, a correlação entre os estilos parentais e esquemas iniciais desadaptativos da referida amostra.

De acordo com os dados sociodemográficos e mediante tabela abaixo (01), torna -se evidente que dentre os 11 participantes da pesquisa detidos por tráfico, a média de idade dos participantes variou entre a faixa etária de 24 a 54 anos de idade $(\mathrm{M}=34,21$ e $\mathrm{DP}=7,43$ ); o nível de escolaridade prevalente entre eles resultou em uma variância entre ensino fundamental incompleto e ensino médio incompleto; no que diz respeito ao estado civil a maioria (05) dos integrantes se apresentou como solteiro. $\mathrm{O}$ referido crime resulta em um tempo médio de sentença que varia entre 01 ano e dois meses a 14 anos e 01 mês $(\mathrm{M}=4,48$ e $\mathrm{DP}=$ $3.86)$.

Tabela 01 - Dados sociodemográfico presos por tráfico

\begin{tabular}{lcccc}
\hline & Mínimo & Máximo & Média & Desvio Padrão \\
\hline Idade do entrevistado & 24 & 54 & 34,21 & 7,434 \\
Escolaridade & 2 & 6 & 3,00 & 1,240 \\
Estado Civil & 1 & 3 & 1,71 & 0,825 \\
Tempo de Sentença (anos) & 1,2 & 14,1 & 4,485 & 3,8620 \\
\hline
\end{tabular}

Fonte: Elaborado pelas autoras a partir dos resultados da pesquisa.

Logo, a média de idade dos 11 participantes detidos por roubo tabela (02) variou entre a faixa etária de 19 a 44 anos de idade $(\mathrm{M}=28,91$ e $\mathrm{DP}=8,01)$; o nível de escolaridade prevalente entre a população resultou em uma variância entre ensino fundamental incompleto e ensino médio incompleto; no que diz respeito ao estado civil, a maioria (08) dos integrantes se declarou como solteiro. O referido crime resulta em um tempo médio de sentença que varia entre 06 anos e três meses a 30 anos $(\mathrm{M}=16,04$ e $\mathrm{DP}=8,15)$.

Vale ressaltar que, dentre todos os 22 detentos, apenas 01 dos participantes ingressou no ensino superior, não chegando a findá-lo. 
Tabela 02 - Dados sociodemográfico presos por roubo

\begin{tabular}{lcccc}
\hline & Mínimo & Máximo & Média & Desvio Padrão \\
\hline Idade do entrevistado & 19 & 44 & 28,91 & 8,018 \\
Escolaridade & 2 & 5 & 3,55 & 1,036 \\
Estado Civil & 1 & 3 & 1,36 & 0,674 \\
Tempo de Sentença & 6,3 & 30 & 16,045 & 8,1595 \\
\hline
\end{tabular}

Fonte: Elaborado pelas autoras a partir dos resultados da pesquisa.

Após a coleta dos dados, as amostras foram avaliadas estatisticamente, utilizando-se com o auxílio das ferramentas: IBM SPSS Statistic 22, de acordo com os resultados do t-Student optou-se pela utilização de testes paramétricos, ficou evidente que a metade das variáveis apresentaram padrões consideráveis de normalidade, com base nos resultados dos valores de assimetria e curtose entre 1 e -1, prova de Shapiro - Wilk com significância > 0.05 e a correlação de Pearson.

Com relação aos resultados vinculados e à homogeneidade e normalidade, esses indicaram a adequação dos dados para utilização de estatísticas paramétricas, tendo sido empregada a técnica da correlação de Pearson para a verificação de existência de correlação entre os esquemas iniciais desadaptativos e os estilos parentais.

De acordo com o teste paramétrico, nenhuma das variáveis avaliadas apresentaram diferenças significativas entre os dois grupos avaliados, ou seja, não houve discrepâncias significativas entre os esquemas iniciais desadaptativos e estilos parentais prevalentes entre os presos por roubo e tráfico. No entanto, os esquemas que mais prevaleceram entre as duas amostras estão relacionados aos domínios IV e V, a saber: autossacrifício, padrões inflexíveis, busca por aprovação, negativismo e postura punitiva.

Com relação ao estilos parentais dos presos por roubo e dos presos por tráfico ficou evidente uma proximidade entre eles, de acordo com a amostra prevaleceram os seguintes estilos parentais nos detentos por roubo: monitoria positiva da mãe $(\mathrm{M}=7,55$ e $\mathrm{DP}=2,65$ ) comportamento moral da mãe $(\mathrm{M}=7,82$ e $\mathrm{DP}=2,44)$; monitoria negativa da mãe $(\mathrm{M}=5,18$ e $\mathrm{DP}=2,22)$; monitoria positiva do pai $(\mathrm{M}=6,36$ e $\mathrm{DP}=3,66)$; comportamento moral do pai $(\mathrm{M}=6,73 \mathrm{DP}=$ $3,87)$; negligência do pai $(\mathrm{M}=5,55$ e $\mathrm{DP}=$ $2,80)$ monitoria negativa da mãe ( $M=4,82$ e $\mathrm{DP}=2,99$ ). Quanto à amostra de presos por tráfico os dados demonstram uma prevalência de estilos parentais de monitoria positiva da mãe $(\mathrm{M}=9,27$ e $\mathrm{DP}=$ $2,86)$; comportamento moral da mãe $(\mathrm{M}=$ $8,64$ e $\mathrm{DP}=3,00)$; monitoria negativa da 
mãe $(\mathrm{M}=7,00$ e $\mathrm{DP}=3,03)$; monitoria positiva do pai $(\mathrm{M}=6,27$ e $\mathrm{DP}=4,36)$; comportamento moral do pai $(\mathrm{M}=8,45 \mathrm{e}$ $\mathrm{DP}=3,69)$; negligência do pai $(\mathrm{M}=4,91 \mathrm{e}$ $\mathrm{DP}=3,91)$ e monitoria negativa do pai $(\mathrm{M}=$ 5,73 e $\mathrm{DP}=3,06$ ).

Todavia, com base na correlação de Spearman entre os estilos parentais e os esquemas inicias desadaptativos presente nesta população, pode-se evidenciar correlações positivas entre os estilos parentais e os esquemas inicias desadaptativos, conforme pode ser observado na tabela abaixo (03).

Tabela 03 - Correlação entre Estilos Parentais e Esquemas Iniciais Desadaptativos Domínio I e II.

\begin{tabular}{ccccc}
\hline & $\begin{array}{c}\text { Privação } \\
\text { emocional } \\
\text { R }\end{array}$ & $\begin{array}{c}\text { Desconfiança e } \\
\text { abuso } \\
\mathbf{R}\end{array}$ & $\begin{array}{c}\text { Dependência e } \\
\text { Incompetência } \\
\mathbf{R}\end{array}$ & Vulnerabilidade \\
\hline $\begin{array}{c}\text { Negligência } \\
\text { Mãe }\end{array}$ & - & $450^{*}$ & $460^{*}$ & R \\
$\begin{array}{c}\text { Abuso Físico } \\
\text { Mãe } \\
\text { Negligência }-\end{array}$ & - & - & - & $530^{*}$ \\
Pai & $437^{*}$ & $426^{*}$ & - & $424 *$ \\
\hline
\end{tabular}

Fonte: Correlação de Pearson.

Nota: $\mathrm{R}=\mathrm{O}$ coeficiente de correlação de Pearson

Conforme tabela acima, percebe-se que estilos parentais de negligência da mãe possui correlação positiva com os esquemas de desconfiança e abuso e dependência/incompetência; estilos parentais de abuso físico da mãe possui correlação positiva com esquema de vulnerabilidade. Logo, estilo parental de negligência do pai apresenta correlação positiva com os esquemas de: privação emocional, desconfiança/abuso e vulnerabilidade e que os estilos parentais de monitoria negativa do pai apresentam correlação positiva com esquema de dependência e incompetência.

Logo, abaixo apresentamos a tabela 04 que descreve as correlações dos estilos parentais com esquemas do domínio III e IV. 
Tabela 04 - Correlação entre Estilos Parentais e Esquemas Iniciais Desadaptativos Domínio III e V.

\begin{tabular}{|c|c|c|c|c|c|c|c|}
\hline & $\begin{array}{c}\text { Inibição } \\
\text { emocional } \\
\text { R }\end{array}$ & $\begin{array}{c}\text { Padrões } \\
\text { inflexíveis } \\
\text { R }\end{array}$ & $\begin{array}{c}\text { Grandio- } \\
\text { sidade/ } \\
\text { Mereci- } \\
\text { mento } \\
\text { R }\end{array}$ & $\begin{array}{c}\text { Autocontrole/ } \\
\text { Autodisciplina } \\
\text { Insuficientes } \\
\text { R }\end{array}$ & $\begin{array}{c}\text { Busca } \\
\text { de } \\
\text { Aprova- } \\
\text { ção } \\
\text { R }\end{array}$ & $\begin{array}{l}\text { Negati- } \\
\text { vismo } \\
\text { R }\end{array}$ & $\begin{array}{l}\text { Postura } \\
\text { punitiva }\end{array}$ \\
\hline $\begin{array}{c}\text { Monitoria } \\
\text { Positiva Mãe }\end{array}$ & $-599 *$ & - & $-459 *$ & - & - & $-476^{*}$ & - \\
\hline $\begin{array}{l}\text { Negligência } \\
\text { Mãe }\end{array}$ & $438^{*}$ & - & - & - & - & $481 *$ & \\
\hline $\begin{array}{c}\text { Abuso físico } \\
\text { Mãe }\end{array}$ & - & - & - & $494 *$ & - & - & - \\
\hline $\begin{array}{c}\text { Comportamento } \\
\text { moral } \\
\text { Pai }\end{array}$ & - & - & - & - & - & - & $561 *$ \\
\hline Negligência Pai & - & - & - & - & $450 *$ & - & - \\
\hline $\begin{array}{c}\text { Disciplina } \\
\text { Relaxada Pai }\end{array}$ & - & - & - & - & $441^{*}$ & - & - \\
\hline
\end{tabular}

Fonte: Correlação de Pearson.

Nota: $\mathrm{R}=\mathrm{O}$ coeficiente de correlação de Pearson

Constatou-se que a monitoria positiva da mãe possui uma relação negativa com os EIDs de inibição emocional, grandiosidade/merecimento e negativismo; os comportamentos de negligência da mãe apresentam correlação positiva com os esquemas de inibição emocional com negativismo; estilos parentais de abuso físico da mãe apresentam correlação positiva com esquemas de autocontrole/autodisciplina insuficiente; o estilo parental da mãe possui correlação positiva com os esquemas de padrões inflexíveis. Foi possível evidenciar que os estilos parentais de comportamento moral do pai possuem correlação positiva com os esquemas de postura punitiva; comportamentos de negligência do pai possuem correlação positiva com os esquemas de busca de aprovação; comportamento de disciplina relaxada do pai possui correlação positiva com o esquema de busca de aprovação.

\section{5 - Discussão dos Resultados}

Em relação aos dados sociodemográficos, percebeu-se que nenhum dos participantes chegou a concluir o ensino superior, dentre os detentos por roubo e tráfico o nível de escolaridade prevalente resultou em uma variância entre ensino fundamental incompleto e ensino médio incompleto. De acordo, com pesquisas realizadas durante os anos de 2010 e 2011 foram desenvolvidos estudos no estado de São Paulo e do Rio de Janeiro 
por instituições que integram a Rede de Justiça Criminal, buscando algumas características de detentos. Esta pesquisa foi apoiada pela Open Society Foundations, e, de acordo com dados divulgados, $75,7 \%$ dos indivíduos apresentaram escolaridade até o primeiro grau completo, $20,9 \%$ com ensino médio e apenas $1,8 \%$ com ensino superior, o que vem de encontro com os resultados encontrados na atual pesquisa, tendo em vista que, ao avaliar os dados, foi possível evidenciar que apenas um dos detentos havia ingressado em uma instituição de ensino superior, não chegando, porém, a formar-se.

Outra característica de aspecto sociodemográfico aparece atrelada a questão do estado civil da amostra pesquisada, pois, a maioria dos participantes declarou seu estado civil como solteiro, Andriola (2016), ressalta a importância do manejo no que diz respeito a termos relacionais com estes indivíduos, pois, os mesmos tendem a apresentar dificuldades nos relacionamentos interpessoais, inclusive de acordo com Young; Klosklko e Weishaar (2008), os esquemas do domínio IV (direcionamento para o outro) e do domínio V (supervigilância e inibição) que identificouse como predominantes nesta pesquisa, alteram o modo de posicionar-se em relação ao outro. Sabe-se que não foi a finalidade desta pesquisa explorar as relações interpessoais e conjugais destes indivíduos, mas os esquemas afetam a realidade como um todo, sua maneira de ser e agir no mundo. Então, trabalhos realizados recentemente têm buscado avaliar os esquemas iniciais desadaptativos nos mais diversos contextos, como, por exemplo, no ambiente conjugal (Paim, Madalena \& Falcke, 2012).

A priori, os resultados desta pesquisa apontam para uma similaridade entre os esquemas iniciais desadaptativos e estilos parentais prevalentes em ambas as populações, os esquemas que mais prevaleceram dentre estas populações foram: autossacrifício, padrões inflexíveis, busca por aprovação, negativismo e postura punitiva. Do mesmo modo, em uma pesquisa desenvolvida por Brazão, Rijo, Salvador e Gouveia (2017), envolvendo a população prisional; as distorções cognitivas e os esquemas iniciais desadaptativos em presidiários do sexo masculino, também não foram encontradas diferenças significativas quanto aos esquemas, logo, estes pesquisadores propuseram aos participantes um programa pró social sobre distorções cognitivas e esquemas iniciais desadaptativos, que conta com constructos da perspectiva teórica proposta por Young e ao avalia-lo, evidenciou-se um aumento significativo da apresentação de pensamentos adaptativos e um decréscimo significativo das distorções 
cognitivas e esquemas desadaptativos no decorrer do tempo.

Diante disto, Wainer et al. (2013) propõe que a ativação dos esquemas faz com que o indivíduo interprete a realidade baseado nestes, ou seja, suas ações, pensamentos e sentimentos sofrem influência de seus EIDs, e, portanto acredita-se que de acordo com a experiência em ambientes prisionais, que a personalidade tanto dos presos por roubo quanto dos presos por tráfico, apresentem semelhanças e que isto tenha contribuído para que não houvesse evidências, bem como, esquemas e estilos parentais diferentes entre ambas as populações.

Entretanto, a partir destas associações faz-se necessário compreender a relação existente entre os esquemas iniciais desadaptativos e os estilos parentais presentes nessa população, com os comportamentos delitivos cometidos pelos mesmos e estruturas de sua personalidade. Além disso, em se tratando de personalidade é importante buscar identificar suas distorções cognitivas e pensamentos, pois, postula-se que $\mathrm{o}$ pensamento criminoso e o comportamento criminoso estejam associados, por tanto a mudança do pensamento torna-se fundamental para a mudança do comportamento (Landenberger \& Lipsey, 2005, como citado em, Brazão, Rijo, Salvador \& Gouveia 2017).
Nesta pesquisa foi associada a aplicação do IEP com a aplicação do YSQS3, sendo possível evidenciar, na prática, que os estilos parentais contribuíram para que alguns esquemas fossem estabelecidos. No modelo teórico de práticas educativas que compõem o estilo parental, a autora Gomide (2006), define alguns conjuntos de práticas educativas utilizadas pelos pais na educação dos filhos, cinco delas relacionadas a comportamentos antissociais, a saber: abuso físico, punição inconsciente, disciplina relaxada, monitoria negativa e negligência; e duas que contribuem para que sejam desenvolvidos comportamentos pró-sociais, a monitoria positiva e o comportamento moral.

$\mathrm{Na}$ amostra foi possível evidenciar que alguns dos esquemas que prevaleceram possuíam correlação com os estilos parentais apresentados, evidenciou-se uma correlação negativa entre os esquemas de inibição

emocional; grandiosidade/merecimento e negativismo quando atrelados ao estilo parental de monitoria positiva da mãe, ou seja, práticas parentais que envolvem a pré disposição de atenção e conhecimento dos pais acerca de onde seu filho está e das atividades que desenvolvem, bem como as demonstrações de afeto e carinho, contribuem para que necessidades básicas sejam supridas e evitam o desenvolvimento dos esquemas mencionados (Gomide, 2006). 
Do mesmo modo Young, Kloslko e Weishaar (2008), reconhecem que cada indivíduo apresenta uma "arquitetura psíquica" oriunda pela interação de seu temperamento, nível de necessidades emocionais básicas em interações ambientais e que pais e educadores que fornecem medidas satisfatórias de apego, carinho, segurança, conforto emocional, capacidade de acalmar as ansiedades e impulsividades da criança, contribuem de forma significativa para sua estabilidade emocional e essa criança, por sua vez, levará essa "base segura" no decorrer de sua vida. Inclusive Mombelli et al. (2014), mencionam que os pais deveriam oportunizar às crianças condições que propiciem um ambiente e estrutura familiar adequada, para que se sintam seguras. De acordo com os autores, isso influência para que haja um crescimento positivo. Pensando a partir da correlação negativa dos esquemas de inibição emocional, grandiosidade/merecimento e negativismo com o estilo parental de monitoria positiva da mãe, ratifica-se em prática este conceito.

Por conseguinte, Young, Kloslko e Weishaar (2008), classificam o negativismo como um dos esquemas do domínio $\mathrm{V}$, no qual a família de origem pode ser considerada como punitiva, perfeccionista e busca evitar "erros" decorrentes de atividades prazerosas. Em regra, essas famílias apresentam preocupação exacerbada com relação à possibilidade dos filhos errarem ao realizarem escolhas e ao desenvolverem ações, fazendo com que “exagerem” na vigilância. Indivíduos com esquema nesse domínio omitem seus impulsos e apresentam rígidas regras internalizadas, via de regra a infância deles pode ter sido marcada pela severidade, rigidez e repressões em que o autocontrole e a própria negação foram predominantes sobre a vontade do indivíduo. Assim sendo, destaca-se que na presente amostra um dos esquemas prevalentes foi o negativismo.

Segundo Young, Kloslko e Weishaar (2008), o esquema de busca de aprovação pertence ao domínio $\mathrm{V}$ e surge atrelado aos estilos parentais de negligência e disciplina relaxada do pai, nestes estilos parentais evidencia-se estruturas familiares onde os pais não estão atentos às necessidades dos filhos. De acordo com Wainer et al. (2016), quando as necessidades básicas não são supridas, originam-se esquemas. No referido domínio, o autor estabelece como necessária a relação em que cuidadores sejam espontâneos e honestos com a expressão emocional e que incentivem a criança a se expressar e a falar sobre os seus sentimentos. Percebe-se que justamente ocorre o contrário no estilo parental de disciplina relaxada, pois neste os pais assumem uma posição indiferente com relação ao comportamento dos filhos, não 
fazendo valer sequer as regras que eles mesmos estabelecem (Gomide, 2006).

Conforme mencionado acima, os esquemas prevalentes na amostra foram identificados e associados ao domínio $\mathrm{V}$ da teoria de esquemas, do mesmo modo, o esquema de postura punitiva que surge atrelado ao comportamento moral do pai, deficiências envolvendo o comportamento moral dos pais resultam em dificuldades na distinção do que é certo do que é errado, fazem com que sentimento de culpa e o desenvolvimento de empatia e ações honestas sejam prejudicados, uma vez que a população da atual pesquisa refere-se a comportamentos delitivos. Sendo assim, percebe-se na prática dos indivíduos consequências dessas "deficiências" em sua personalidade (Gomide, 2006).

Em suma, os esquemas de autossacrifício, padrões inflexíveis, busca de aprovação, negativismo e postura punitiva encontrados na amostra e correlacionados anteriormente contribuem para ratificar a influência dos pressupostos de Wainer et al. (2016), em que os autores mencionam que a estruturação da personalidade é compreendida por um processo natural e que tem suas fundações em bases genéticas, que contribuem para a definição do temperamento, das tendências comportamentais, afetivas, cognitivas e motivacionais que sofreram os efeitos do ambiente, ou seja, das aprendizagens e experiências durante o decorrer da vida.

Procurou-se realizar pesquisas que apresentavam associações de crime por tráfico e crimes de roubo, e, nessa perspectiva, foi possível evidenciar que existem várias notícias em jornais em que os dois crimes aparecem associados. Infelizmente, pesquisas e produções literárias que envolvam as duas populações são escassas, o que nos desperta para a necessidade de desenvolver pesquisas com o intuito de saber se, além de esquemas e estilos parentais similares, não existe uma correlação entre os crimes cometidos e se os detentos por crime de tráfico também não acabam tendo passagens por crime de roubo e vice-versa.

\section{6 - Considerações Finais}

A pesquisa demonstrou que presos por roubo e tráfico não apresentam diferenças significativas em seus esquemas iniciais desadaptativos e estilos parentais, no entanto foi possível evidenciar a influência dos estilos parentais no desenvolvimento de esquemas. Sendo assim, estes resultados podem auxiliar na prevenção e ressignificação dos comportamentos desadaptativos apresentados, isto porque, a partir de premissas da teoria de esquemas, quando um determinado indivíduo está em 
acompanhamento terapêutico, o psicólogo assume a tarefa terapêutica de, em meio as suas limitações, tentar ofertar e trabalhar com o paciente as necessidades emocionais. Necessidades essas que, durante o período de infância e adolescência, apresentaram defasagens e afetam de maneira significativa a sua relação consigo e para com o meio que está inserido. Postula-se que a estrutura de personalidade de ambas as classes de detentos possui similaridades e acredita-se que, em amostras de populações diferenciadas, o resultado encontrado possa ser diferente.
Deste modo, os resultados desta pesquisa apontam para a necessidade de se investir em investigações que contribuam para a compreensão da estrutura psíquica e personalidade de presos por roubo e tráfico. Vale ressaltar, ainda, que uma das limitações do estudo está relacionada ao número de pesquisas que envolvem uma temática similar. Por isso, estudos futuros sobre a personalidade destes indivíduos podem fornecer subsídios teóricos que permitem uma melhor exploração e associação entre o crime de roubo e tráfico.

\section{Referências}

Andriola, R. (2016). Estratégias Terapêuticas: Reparentalização Limitada e Confrontação Empática. In: Wainer, R. et al. (Org.). Terapia Cognitiva Focada em Esquemas: Integração em Psicoterapia. (pp. 298-301), Porto Alegre, Artmed.

Baumrind, D. (1966). Effects of authoritative control of child behavior. Child Development, 45, p. 887-907. https://doi.org/10.2307/1126611.

Boeckel, M. G. \& Sarriera, J. C. (2006). Estilos parentais, estilos atribucionais e bem-estar psicológico em jovens universitários. Revista Brasileira de Crescimento $e$ Desenvolvimento Humano, 16(3), p. 53-65, 2006. https://doi.org/10.7322/jhgd.19802.

Beck, J. S (1997). Terapia Cognitiva: teoria e prática. Porto Alegre, Artmed.

Brasil (1940). Decreto-Lei no 2.848, de 7 de dezembro de 1940. Código Penal. Diário Oficial da União, Rio de Janeiro, RJ.

Brasil (2006). Lei no 11.343, de 23 de agosto de 2006. Institui o Sistema Nacional de Políticas Públicas sobre Drogas - SISNAD; prescreve medidas para prevenção do uso indevido, atenção e reinserção social de usuários e dependentes de drogas; estabelece normas para repressão à produção não autorizada e ao tráfico ilícito de drogas; define crimes e dá outras providências. Diário Oficial da União, Brasília, DF.

Brazão, N., Rijo, D., Salvador, M. C. \& Gouveia, J. (2007). Os efeitos do programa pró-social crescente sobre distorções cognitivas e esquemas desadaptativos precoces ao longo do tempo na prisão masculina. Unidade de Investigação Cognitivo Comportamental, Centro 
de Investigação e Intervenção. Faculdade de Psicologia e Ciências da Educação da Universidade de Coimbra.

Cardoso, J. \& Verissimo, M. (2013). Estilos parentais e relações de vinculação. Análise Psicológica, 31(4), p. 41-49.

Cazassa, M. J.; Oliveira, M. S. Terapia focada em esquemas: Conceituação e pesquisas. Revista Psiquiatria Clínica, 5(5), p. 187-195. https://doi.org/10.1590/S0101-60832008000500003.

CFP - Conselho Federal de Psicologia (20144). Código de Ética Profissional do Psicólogo. Brasília, CFP.

Fioravante, M. G. \& Castañon, G. A. (2014). Uma Análise Comparativa entre a Terapia Cognitiva de Aaron Beck e a Terapia do Esquema de Jeffrey E. Young. 2014. 42 f. Dissertação (Especialização em em Psicologia) - Universidade Federal de Juiz de Fora, Juiz de Fora.

Gil, A. C. (2008). Como Elaborar Projetos de Pesquisa, São Paulo, Atlas.

Gomide, P. I. C. (2006). IEP: Inventários de Estilos Parentais - Modelo teórico: Manual de aplicação, apuração e interpretação. Petrópolis, Vozes.

Isoppo, G. S. L. (2012). Terapia focada em esquemas de personalidade narcisista: um entendimento a cerca deste transtorno. Monografia (Especialização em Psicologia Clínica) - Universidade Federal do Rio Grande do Sul, Porto Alegre.

Lila, T. F. V. B. (2009). Autoestima e percepção das práticas parentais na fase final da adolescência. 2009. 185 f. Dissertação (Mestrado em Psicologia) - Universidade de Lisboa, Lisboa, Portugal.

Lubi, A. P. L. (2003). Estilo parental e comportamento socialmente habilidoso da criança com pares. In: Brandão, M. Z. S. et al. (Org.). Sobre comportamento e cognição: A história e os avanços, a seleção por consequências em ação, (pp. 536-541), Santo André, ESETEC.

Macarini, S. M., et al (2010). Práticas parentais: uma revisão da literatura brasileira. Arquivos Brasileiros de Psicologia, 62(1), p. 227-236.

Mafra, F. (2012). Constituição: conceito. Princípios fundamentais do estado democrático de direito. Âmbito Jurídico [online], 15(105). Disponível em: <http://www.ambitojuridico.com.br/site/?n_link=revista_artigos_leitura\&artigo_id=1228 2>. Acesso em: 17 jun. 2017.

Mendes, M. E. G. \& Vieira, N. B. (2012). As Causas e Efeitos da Rotulação de "Desviantes" na Sociedade. ViaJus, 6(4), p. 44-49.

Mombeli, M. A. et al (2014). Habilidades sociais parentais e o estresse infantil. Revista Perspectivas em Psicologia, 18(2), p. 33-38.

Mondin, E. M. C. (2008). Práticas educativas parentais e seus efeitos na criação dos filhos. Psicologia e Argumentação, 26(54), p. 233-244. https://doi.org/10.7213/rpa.v26i54.19885. 
Paim, K., Madalena, M. \& Falcke, D. (2012). Esquemas Iniciais Desadaptativos na violência conjugal. Revista Brasileira de Terapia Cognitiva, 8(1), p. 31-39.

Rijo, D. M. B. (2009). Esquemas Mal-Adaptativos Precoces: Validação de conceito e dos métodos de avaliação. Dissertação (Mestrado em Psicologia Clínica) - Universidade de Coimbra, Coimbra, Portugal.

Rijo, D., Brazão, N. \& Capinha, M. (2016). A Terapia do esquema para indivíduos antissociais. In: WAINER, R. et al. (Org). Terapia Cognitiva Focada em Esquemas: Integração em Psicoterapia. (pp. 155-183), Porto Alegre, Artmed.

Rocha, M. C. O., Formiga, N. S. \& Lopes, E. J. (2014). Esquemas de personalidade mais prevalentes em indivíduos que praticaram crimes. Psicologia revista, 23(2), p. 197-217.

Rocha, G. V. M. \& Carvalho, E. G. (2012). Comparação de estilos parentais de homicidas reais e homicidas virtuais. Tuiuti: Ciência e Cultura, 45, p. 189-204.

Sampaio, I. T. A. (2007). Inventário de Estilos Parentais (IEP): um novo instrumento para avaliar as relações entre pais e filhos. Psicologia-USF, 12(1), p. 125-126. https://doi.org/10.1590/S1413-82712007000100015

Silva, M. A. D. F. (2013). Tipos de Comportamentos Desviantes. Psicologado. Disponível em: $<$ https://psicologado.com/atuacao/psicologia-juridica/tipos-de-comportamentosdesviantes>. Acesso em: 17 jun. 2017.

Silveiras, R. S. \& Gouvêa, G. F. P. (2012). Indivíduo, coerção e sociedade: Estudo da coerção social a partir de Durkheim, Bourdieu e Foucault. Monografia (Graduação em Ciências Sociais) - Universidade Estadual de Campinas, Campinas - SP.

Velho, G. (2003). Desvio e divergência: uma crítica da patologia social. Rio de Janeiro, Jorge Zahar.

Wainer, R. et al. (2013). Esquemas Iniciais Desadaptativos no transtorno por uso de álcool. Revista Brasileira de Terapias Cognitivas, 9(2), p. 101-107.

Wainer, R. et al. (Org) (2016). Terapia Cognitiva Focada em Esquemas: Integração em Psicoterapia. São Paulo, Artmed.

Wainer, R. \& Rijo, D. (2016). O modelo teórico: esquemas iniciais desadaptativos, estilos de enfrentamento e modos esquemáticos. In: Wainer, R. et al. (Org). Terapia Cognitiva Focada em Esquemas: Integração em Psicoterapia, (pp. 112-130), São Paulo, Artmed.

Young, J. E. (2003). Terapia Cognitiva para Transtornos da Personalidade. Porto Alegre, Artmed.

Young, J. E., Klasko, J. S. \& Weishaar, M. E. (2008). Terapia do esquema: Guia de técnicas cognitivo-comportamentais inovadoras. Porto Alegre, Artmed. 
Ana Paula Costa de Cristo, acadêmica Curso de Psicologia do Centro Universitário Fundação Assis Gurgacz, Cascavel - PR. E-mail: anapaulacostadecristo@gmail.com

Dayane Denck Froeder, acadêmica Curso de Psicologia do Centro Universitário Fundação Assis Gurgacz, Cascavel - PR. E-mail: dayanedenckf@gmail.com

Adriana Aparecida Garbin, psicóloga Clínica e Forense, mestre em Psicologia pela Universidade Tuiuti do Paraná, Curitiba-PR, membro da Diretoria da Associação de Terapia Cognitiva do Paraná - ATC/PR, Psicóloga Licenciada do Departamento Penitenciário do Estado do Paraná - DEPEN, docente dos cursos de Psicologia do Centro Universitário Fundação Assis Gurgacz, Cascavel-PR. E-mail: aagarbin @ hotmail.com

Recebido em: 19/04/2017

Aprovado em: 15/12/2017 